\title{
Clinical and Functional Lung Parameters Associated With Frequent Exacerbator Phenotype in Subjects With Severe COPD
}

\author{
Alberto Capozzolo MD, Pierluigi Carratù MD PhD, Silvano Dragonieri MD PhD, \\ Vito Antonio Falcone MD, Vitaliano Nicola Quaranta MD, Vito Liotino, Giuseppina D'Alba MD, \\ Giorgio Castellana MD, and Onofrio Resta MD
}

\begin{abstract}
BACKGROUND: COPD is currently recognized as a syndrome associated with a high prevalence of comorbidities and various phenotypes. Exacerbations are very important events in the clinical history of COPD because they drive the decline in lung function. In the present study, we aim to identify whether there are any clinical and functional specific features of frequent exacerbators in a population of patients with severe COPD. METHODS: We conducted a cross-sectional, case control study. All subjects had Global Initiative for Chronic Obstructive Lung Disease (GOLD) stage 3 or 4 COPD $\left(\mathrm{FEV}_{1}<50 \%\right.$ predicted). Frequent exacerbators ( $n=183$ ) reported $\geq 2$ exacerbations or $\geq 1$ determining hospitalization during the previous 12 months, and infrequent exacerbators $(n=162)$ reported $<2$ exacerbations over the last 12 months without hospitalization. Multivariate logistic regression was performed to determine the clinical and functional factors significantly associated with frequent exacerbator status. RESULTS: Frequent exacerbators had a significantly lower inspiratory capacity percentage predicted. The Motley index (residual volume/total lung capacity percentage) was significantly increased in frequent exacerbators. Infrequent exacerbators had lower Modified Medical Research Council dyspnea scale and BODE index than frequent exacerbators. In the multivariate model, a reduced inspiratory capacity percentage predicted and an increase of residual volume/total lung capacity percentage, BODE index and Modified Medical Research Council dyspnea scale were associated with the frequent exacerbation phenotype. CONCLUSIONS: Static hyperinflation and respiratory disability, measured by Motley index and Modified Medical Research Council dyspnea scale, respectively, in the same way as the multidimensional BODE index staging system, were independently associated with frequent exacerbation status in subjects with severe COPD. Key words: COPD exacerbations; COPD phenotypes; respiratory disease; body plethysmography; spirometry. [Respir Care 2017;62(5):572-578. (C) 2017 Daedalus Enterprises]
\end{abstract}

\section{Introduction}

COPD is a heterogeneous disorder that is projected to become the fourth leading cause of death globally by $2030 .{ }^{1}$

\footnotetext{
The authors are affiliated with the Institute of Respiratory Disease, Department of Cardiac, Thoracic, and Vascular Science, University of Medicine, Bari, Italy.

The authors have disclosed no conflicts of interest.
}

Correspondence: Alberto Capozzolo MD, Piazzale Giulio Cesare n. 11, 70124 Bari, Italy. E-mail: alberto.uniba@gmail.com.

DOI: $10.4187 /$ respcare. 05278
COPD is currently recognized as a syndrome associated with a high prevalence of comorbidities and various phenotypes. ${ }^{2}$ The pathophysiologic hallmark of COPD is exercise intolerance and exertional dyspnea, which are probably due to complex interactions among impaired ventilatory, cardiovascular, and peripheral muscle responses. The leading cause of respiratory muscle dysfunction in patients with COPD is the mechanical handicap caused by lung hyperinflation. ${ }^{3}$ Exacerbations are very important events in the clinical history of COPD because they drive the decline in lung function, ${ }^{4}$ reduce quality of life, ${ }^{5}$ contribute to hospitalization and mortality, and therefore increase costs to the health system. ${ }^{6}$ Nevertheless, we know relatively little about their incidence and their determinants. 


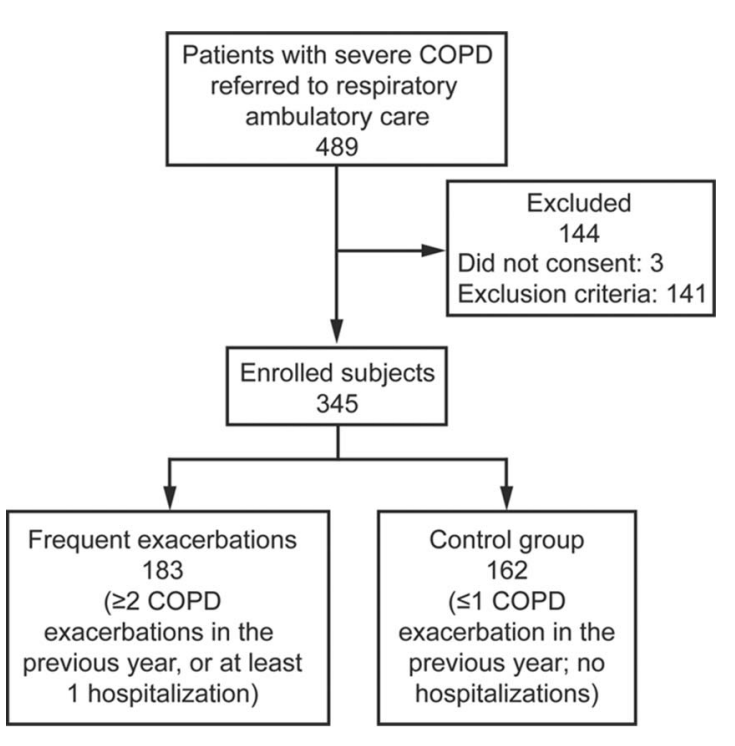

Fig. 1. Flow chart.

In a few studies, increasing GOLD stage, ${ }^{7}$ chronic cough and sputum production, ${ }^{8,9}$ lower $\mathrm{FEV}_{1}$ percent of predicted, ${ }^{7,9-11}$ low forced expiratory flow during the middle half of the FVC maneuver, ${ }^{12}$ enphysematous phenotype, ${ }^{13}$ advanced age, ${ }^{9,11,14}$ BODE category, and clinical depression were associated with the development of exacerbations. ${ }^{11,14-16}$

Clinical experience shows patients living with frequent exacerbations, as opposed to patients in whom this problem is infrequent or absent. Several studies have shown that the number of exacerbations from year to year in a single subject is highly reproducible and that a history of exacerbations predicts future exacerbations, ${ }^{4,17,18}$ potentially indicating a definable phenotype of exacerbation susceptibility. The characterization of these 2 phenotypes within a cohort of subjects with severe COPD could offer further information about why some patients have frequent exacerbation, whereas others remain partly protected. In the present study, we aim to identify whether there are any clinical and functional specific features of frequent exacerbators in a population of patients with severe COPD.

\section{Methods}

\section{Study Design and Subject Population}

The design of the study was cross-sectional, case control (Fig. 1). We studied all consecutive patients with COPD referred to our respiratory ambulatory care between April 2013 and May 2016 who satisfied the selection criteria and provided informed consent according to the Declaration of Helsinki guidelines. Inclusion criteria were: smokers or ex-smokers with a smoking history $\geq 10$ pack-years, age $40-75 \mathrm{y}$, with a diagnosis of severe COPD for $\geq 12$ months,

\section{QUICK LOOK}

\section{Current knowledge}

The annual rate of COPD exacerbations has been estimated to be between 0.5 and 3.5/patient. Exacerbations are more frequent with increasing severity of COPD.

\section{What this paper contributes to our knowledge}

In a population of subjects with severe COPD, high Motley index (residual volume/total lung capacity percentage) and Modified Medical Research Council dyspnea scale were independently associated with frequent exacerbator status. COPD staging by body plethysmography, in severe forms, can differentiate patients at highest risk of exacerbations.

which was defined as Global Initiative for Chronic Obstructive Lung Disease (GOLD) stage 3 or 4: a post-bronchodilator $\mathrm{FEV}_{1} / \mathrm{FVC}<0.70$ and a post-bronchodilator $\mathrm{FEV}_{1}<50 \%$ predicted. ${ }^{19}$ Exclusion criteria included: current or recent lower respiratory tract infection $(<6$ weeks ago); history of asthma; home noninvasive ventilation use; inability to perform the walking test; previous diagnosis of lung cancer, tuberculosis, asbestosis, chronic use of systemic corticosteroids, organ transplantation, lung volume reduction surgery, or previous lung resection; myocardial infarction within the previous 12 months; and known moderate-to-severe renal impairment.

At the enrollment visit, exacerbations or hospitalizations associated with COPD in the previous 12 months were assessed retrospectively by subjects' medical history and subsequently established by review of their medical follow-up records. Exacerbations were defined as "events in the natural course of the disease, characterized by a change in the patients' baseline dyspnea, cough and/or sputum, which is beyond normal day-to-day variations, acute in onset and leading to a change in medication." 20 Subjects with $\geq 2$ reported exacerbations or $\geq 1$ with hospitalization were identified as case subjects (frequent exacerbator group). Subjects with no exacerbations or one exacerbation without hospitalizations were identified as control subjects (infrequent exacerbator group). To calculate pack-years of smoking, the average of number of cigarettes smoked per day was divided by 20 to give packs/day and multiplied by the total number of years of smoking. Ex-smokers were former smokers who had not smoked for $\geq 6$ months.

\section{Pulmonary Function Testing}

Subsequently, pulmonary function measurements were always performed in the same order: first body plethys- 


\section{Factors Associated With Frequent COPD Exacerbator Phenotype}

mography, followed by spirometry. Inspiratory capacity, total lung capacity (TLC), residual volume (RV), and their ratio (RV/TLC percentage) were recorded by body plethysmography (Masterscope, Erich Jaeger, Essen, Germany). $\mathrm{FEV}_{1}$ and $\mathrm{FVC}$ were measured using a spirometry system (Masterscreen-PFT, Erich Jaeger), and $\mathrm{FEV}_{1} / \mathrm{FVC}$ was calculated. A full explanation and training in the performance of each lung function test was given to each subject before the study. All lung function measurements were made according to European Respiratory Society/American Thoracic Society standardizations both before and approximately $20 \mathrm{~min}$ following the administration of inhaled short-acting bronchodilator ( $400 \mu \mathrm{g}$ of salbutamol through a metered-dose inhaler using an Aerochamber spacer). ${ }^{21}$

\section{Clinical Parameters and Medications}

Additional variables assessed during the study were recorded at baseline as follows. Chronic bronchitis was considered present if a person had cough and phlegm production on most days for $\geq 3$ months of the year for $\geq 2 y$. Respiratory disability was assessed using the Modified Medical Research Council dyspnea scale (mMRC). ${ }^{22}$ Body mass index was calculated as $\mathrm{kg} / \mathrm{m}^{2}$. The 6 -min walk test was performed according to the American Thoracic Society guidelines. ${ }^{23}$ BODE index was calculated using the model described by Celli et al. ${ }^{24}$ All subjects underwent arterial blood gas analysis at rest for at least $15 \mathrm{~min}$ on room air, and then $\mathrm{P}_{\mathrm{aO}_{2}}$ and $\mathrm{P}_{\mathrm{aCO}}$ were collected.

A list of current medications was obtained during the study visit and recorded in the following categories as being present or absent: long-acting $\beta_{2}$ agonists, longacting muscarinic antagonists, inhaled corticosteroids, chronic home oxygen use, mucolytics, methylxanthine, hydroxymethylglutaryl-CoA reductase inhibitors (statins), aspirin, diuretics, any anti-hypertensive and anti-arrhythmic medications, $\beta 1$-selective blockers, oral antidiabetic drugs, and proton-pump inhibitors. Finally, the Charlson comorbidity index was calculated according to the specifications described by Charlson et al. ${ }^{25}$ The study was approved by the Bari University General Hospital institutional review committee.

\section{Statistical Analysis}

Univariate comparisons between groups were performed by the Student $t$ test for independent samples and the MannWhitney U test for normally and non-normally distributed variables, respectively. Comparisons between binary and ordinal variables were performed using the Fisher exact test and the chi-square test for trend, respectively. Variables significant at $P \leq .20$ were further combined and analyzed by multivariate logistic regression analysis, including adjustment for $\mathrm{FEV}_{1}$ percent of predicted. The
Table 1. Exacerbation Incidence in the Previous 12 Months in 345 Subjects With COPD

\begin{tabular}{lr}
\hline \hline \multicolumn{1}{c}{ Categories } & $n(\%)$ \\
\hline No exacerbations & $78(23)$ \\
1 exacerbation without hospitalization & $84(24)$ \\
$\geq 2$ exacerbations without hospitalization & $109(32)$ \\
$\geq 1$ exacerbations with hospitalization & $74(21)$ \\
\hline
\end{tabular}

relationships between the number of exacerbation episodes during the previous 12 months and the RV/TLC percentage value and mMRC value were also assessed using Spearman's rank correlation coefficient. Medication use variables were excluded in the multivariate model due to risk of confounding by indication. A $P$ value of $<.05$ was considered to be significant.

\section{Results}

We enrolled a total of 345 eligible subjects with severe COPD. Incidence of exacerbations is shown in Table 1. The annual rate of COPD exacerbations/subject was 1.51. Characteristics of the study population and univariate comparison between infrequent exacerbators and frequent exacerbators are shown in Table 2. No significant differences were found in age, sex, body mass index, current smoker percentage, pack-years smoked, and presence of chronic cough between frequent exacerbators and infrequent exacerbators. Mean $\mathrm{FEV}_{1} / \mathrm{FVC}$ and TLC percentage predicted values did not change significantly in the 2 populations. Frequent exacerbators had significantly lower inspiratory capacity percentage predicted. Furthermore, RV/TLC percentage was significantly increased in frequent exacerbators. Infrequent exacerbators had lower mMRC and BODE index than frequent exacerbators. No significant differences were reported for 6-min walk distance, $\mathrm{P}_{\mathrm{aO}_{2}}, \mathrm{P}_{\mathrm{aCO}}$, and Charlson comorbidity index between the 2 groups.

The percentage of drug use (Table 3) shows significant high rates of long-acting muscarinic antagonists and inhaled corticosteroid use in subjects with frequent exacerbations. On the contrary, there were no significant differences in the percentage of long-acting $\beta_{2}$ agonists, non-pulmonary medication, and home oxygen use.

In the multivariate model, a reduced inspiratory capacity percentage predicted and an increase of RV/TLC percentage, mMRC score, and BODE index were associated with frequent exacerbator status (Table 4). A positive correlation was found both between mMRC score and frequent exacerbations (Spearman's rho $=0.18, P<.001$; Fig. 2) and between RV/TLC percentage and frequent exacerbations (Spearman's rho $=0.20, P<.001 ;$ Fig. 3). 


\section{Factors Associated With Frequent COPD Exacerbator Phenotype}

Table 2. Clinical Characteristics of Study Subjects

\begin{tabular}{|c|c|c|c|}
\hline Variables & $\begin{array}{l}\text { Infrequent } \\
\text { Exacerbators } \\
(n=162)\end{array}$ & $\begin{array}{c}\text { Frequent } \\
\text { Exacerbators } \\
(n=183)\end{array}$ & $P$ \\
\hline Age, mean \pm SD y & $67.6 \pm 7.4$ & $68.5 \pm 6.9$ & .21 \\
\hline Male sex, \% & 61.1 & 67.2 & .26 \\
\hline Current smokers, $\%$ & 24.0 & 18.5 & .24 \\
\hline Chronic bronchitis, \% & 37.6 & 43.3 & .32 \\
\hline Pack-years, mean \pm SD & $52.8 \pm 24.1$ & $53.7 \pm 23.8$ & .29 \\
\hline $\mathrm{BMI}$, mean $\pm \mathrm{SD} \mathrm{kg} / \mathrm{m}^{2}$ & $26.5 \pm 5.0$ & $25.8 \pm 4.5$ & .67 \\
\hline $\mathrm{P}_{\mathrm{aO}_{2}}$, mean $\pm \mathrm{SD}$ mm Hg & $67.3 \pm 8.4$ & $66.4 \pm 9.3$ & .54 \\
\hline $\mathrm{P}_{\mathrm{aCO}_{2}}$, mean $\pm \mathrm{SD} \mathrm{mm} \mathrm{Hg}$ & $42.7 \pm 4.4$ & $43.5 \pm 4.6$ & .58 \\
\hline $\mathrm{FEV}_{1}$, mean $\pm \mathrm{SD} \%$ predicted & $38.4 \pm 9.1$ & $37.3 \pm 8.3$ & .41 \\
\hline $\mathrm{FVC}$, mean $\pm \mathrm{SD} \%$ predicted & $65.0 \pm 11.0$ & $63.9 \pm 10.0$ & .36 \\
\hline $\mathrm{FEV}_{1} / \mathrm{FVC}$, mean $\pm \mathrm{SD}$ & $0.47 \pm 0.14$ & $0.48 \pm 0.12$ & .41 \\
\hline $\mathrm{IC}$, mean $\pm \mathrm{SD} \%$ predicted & $56.1 \pm 10.1$ & $53.2 \pm 9.4$ & .02 \\
\hline $\mathrm{TLC}$, mean $\pm \mathrm{SD} \%$ predicted & $127.2 \pm 28.2$ & $130.5 \pm 30.6$ & .10 \\
\hline $\mathrm{RV} / \mathrm{TLC}$, mean $\pm \mathrm{SD} \%$ & $57.9 \pm 11.1$ & $62.2 \pm 10.3$ & $<.001$ \\
\hline $6 \mathrm{MWD}$, mean $\pm \mathrm{SD} \mathrm{m}$ & $332.0 \pm 70.1$ & $319.1 \pm 65.6$ & .08 \\
\hline BODE index & $4.1 \pm 1.4$ & $4.5 \pm 1.3$ & .01 \\
\hline mMRC & $2.4 \pm 0.8$ & $2.7 \pm 0.7$ & $<.001$ \\
\hline Charlson comorbidity index & $2.1 \pm 1.1$ & $2.3 \pm 1.2$ & .28 \\
\hline
\end{tabular}

Lung function variables reported are post-bronchodilator values.

BMI $=$ body mass index

IC $=$ inspiratory capacity

TLC $=$ total lung capacity

$\mathrm{RV}=$ residual volume

6MWD $=6$-min walk distance

mMRC $=$ Modified Medical Research Council dyspnea scale $(0-4,4$ representing severe

shortness of breath)

Table 3. Medication Use

\begin{tabular}{lccc}
\hline \hline \multicolumn{1}{c}{ Variables } & $\begin{array}{c}\text { Infrequent } \\
\text { Exacerbators } \\
(n=162)\end{array}$ & $\begin{array}{c}\text { Frequent } \\
\text { Exacerbators } \\
(n=183)\end{array}$ & $P$ \\
\hline Long-acting muscarinic antagonists & 62.3 & 75.4 & .01 \\
Long-acting $\beta$ agonists & 89.5 & 91.8 & .57 \\
Inhaled corticosteroids & 67.9 & 80.9 & .006 \\
Methylxanthine & 1.2 & 2.7 & .45 \\
Aspirin & 24.7 & 26.8 & .71 \\
HMG-CoA reductase inhibitor (statin) & 22.2 & 24.6 & .61 \\
Diuretics & 34.6 & 38.5 & .50 \\
Anti-hypertensive medications & 47.5 & 51.9 & .45 \\
$\beta_{1}$-selective blockers & 21.0 & 23.5 & .61 \\
Anti-arrhythmic medications & 13.5 & 10.9 & .51 \\
Oral antidiabetic drugs & 18.3 & 25.1 & .15 \\
Proton-pump inhibitors & 38.3 & 45.4 & .19 \\
Home oxygen use (current) & 6.2 & 10.4 & .12 \\
\end{tabular}

Data are presented as percentages.

HMG-CoA reductase $=$ hydroxymethylglutaryl-CoA reductase

\section{Discussion}

Exacerbations of COPD cause morbidity, hospital admissions, and mortality, and strongly influence health-related quality of life. A better understanding of the predictors of exacerbations becomes essential for effective
Table 4. Multivariate Model for Frequent Exacerbator Status

\begin{tabular}{lcc}
\hline \hline \multicolumn{1}{c}{ Variables } & OR $(95 \%$ CI $)$ & $P$ \\
\hline IC, \% predicted & $0.74(0.43-0.97)$ & .008 \\
TLC, \% predicted & $0.92(0.61-1.38)$ & .22 \\
RV/TLC, \% & $1.66(1.36-2.07)$ & $<.001$ \\
6MWD, m & $0.72(0.31-1.24)$ & .10 \\
BODE index & $1.47(1.16-1.77)$ & .02 \\
mMRC score & $1.45(1.12-1.91)$ & $<.001$ \\
$\mathrm{FEV}_{1}, \%$ predicted & $0.81(0.59-1.08)$ & .31 \\
& & \\
\hline FEV ${ }_{1} \%$ post-bronchodilator was forced included into the model. & \\
$\mathrm{OR}^{2}$ odds ratio & & \\
$\mathrm{IC}=$ inspiratory capacity & & \\
$\mathrm{TLC}=$ total lung capacity & & \\
$\mathrm{RV}=$ residual volume \\
$6 \mathrm{MWD}=$ 6-min walk distance \\
mMRC $=$ Modified Medical Research Council dyspnea scale \\
\end{tabular}

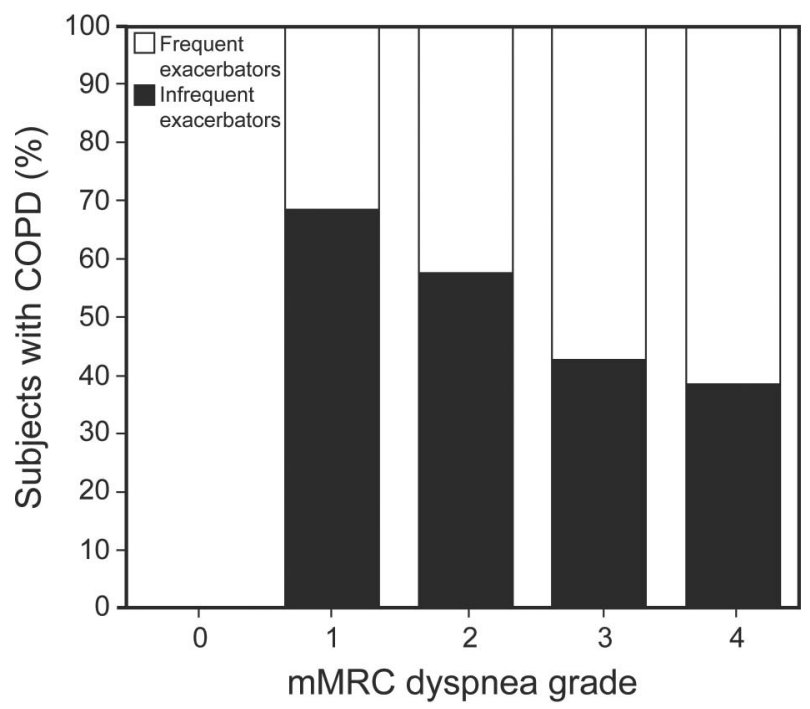

Fig. 2. Modified Medical Research Council dyspnea scale (mMRC) grade entry in relation to the frequency of COPD exacerbations.

implementation of preventive interventions. This study demonstrated that higher RV/TLC, low inspiratory capacity percentage predicted, and high mMRC score were independently associated with frequent exacerbations of COPD, whereas $\mathrm{FEV}_{1}$ was not. The characterization of frequent exacerbators and relatively resistant non-exacerbators in a large observational study has generated some doubts about the association between traditional risk factors and exacerbations. ${ }^{18}$ The results of our study support the evidence in the literature that has led to the definition of these 2 phenotypes of COPD exacerbations and introduce possible risk factors. We observed several findings of note. First, the Motley index (RV/TLC percentage), and not air-flow limitation, was independently associated with frequent exacerbations of COPD, suggesting that the severity of air trapping was more closely linked to frequent 


\section{Factors Associated With Frequent COPD Exacerbator Phenotype}

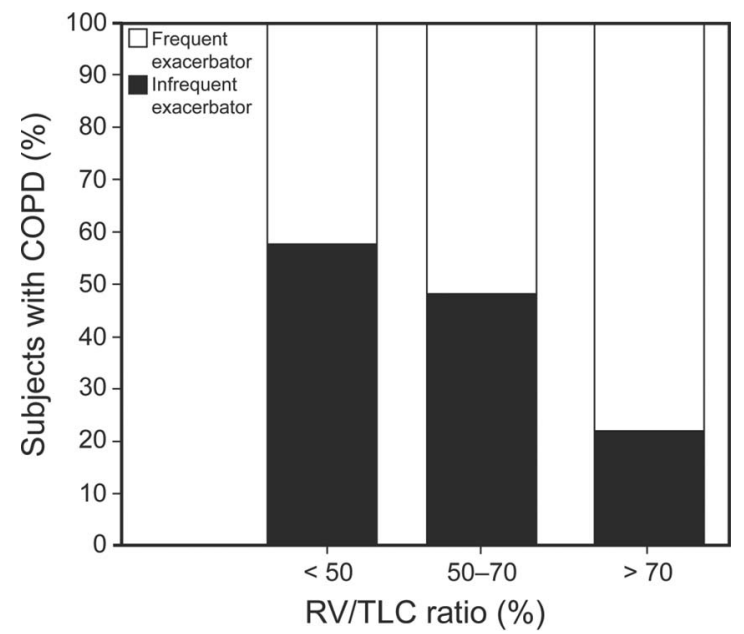

Fig. 3. Residual volume/total lung capacity (RV/TLC) percentage entry in relation to the frequency of COPD exacerbation.

exacerbations than $\mathrm{FEV}_{1}$. Thus, although low $\mathrm{FEV}_{1}$ has been well established as a risk factor for exacerbations, ${ }^{9,10}$ its usefulness may be confined to comparisons between subjects with COPD with many levels of $\mathrm{FEV}_{1}$ impairment in all stages of disease. Additional findings that support the concept of these sub-phenotypes as independent phenomena include the absence of differences in some features such as age, sex, or rates of chronic bronchitis and current smokers between the 2 groups. The lack of association with these historical risk factors may be ascribable to the fact that our cohort was composed of subjects with advanced disease. Furthermore, the association of inspiratory capacity percentage predicted with frequent exacerbation status was not unexpected. It was a significant risk factor for morbidity in these subjects, at least in terms of the number of exacerbation-related hospitalizations. ${ }^{26}$ The inspiratory capacity change reflects the variation of the end-expiratory lung volume that is the operative expression of the functional residual capacity. Hence, the inspiratory capacity reduction is associated with an increase in the end-expiratory lung volume, attesting to static and/or dynamic pulmonary hyperinflation. Whereas static hyperinflation is related to a decreased pulmonary elastance, conversely, elevated ventilatory demand, prolonged pulmonary time constants (due to high lung compliance and/or pulmonary and airway flow resistance), and, most of all, tidal expiratory flow limitation at rest are responsible for dynamic hyperinflation in patients with COPD. ${ }^{27}$ Therefore, patients with COPD with resting expiratory flow limitation, who usually show decreased inspiratory capacity, have more chronic dyspnea. ${ }^{28,29}$ These indices of hyperinflation correlate better than $\mathrm{FEV}_{1}$ with respiratory disability and the resulting activity limitation..$^{30}$ These findings explain in part the difference in the mMRC score between the 2 groups. The significance of the mMRC in predicting exacerbations was already reported by Hurst et $\mathrm{al}^{18}$ and by Wan et al, ${ }^{12}$ as well as the evidence that low mMRC grades were associated with respiratory disability and health status impairment. ${ }^{31}$ Nevertheless, this association may be due in part to the continued reliance on the subjective report of increased shortness of breath in defining exacerbations. Regardless, the association of the mMRC with frequent exacerbator status is suggested by our data analysis.

The association between increased BODE index and frequent exacerbations was not new evidence, but it was highlighted in previous works, ${ }^{14,15}$ showing that the integration of several parameters (clinical and functional) can lead patients to develop more frequent exacerbations. Moreover, previous works have reported that for each quartile increase in BODE index score, there is an increase in the risk for mortality, and also the index predicts mortality more accurately than $\mathrm{FEV}_{1} \cdot{ }^{24,32}$ The BODE index has been shown to correlate well with measures of quality of life, such as the St George Respiratory Questionnaire. ${ }^{33}$

The 6-min walk test is a potentially useful biomarker of disease severity and survival in patients with COPD. ${ }^{34}$ Few data have been reported in the literature concerning the evaluation of distance walked in the 6-min walk test as a predictor of exacerbation. ${ }^{35}$ In the multivariate model, the 6-min walk test was not associated with frequent exacerbations in our subjects with severe COPD. In support of our data, we highlight the work of Polkey et al, ${ }^{36}$ based on the ECLIPSE cohort, in which a reduction in the 6-min walk distance of $\geq 30 \mathrm{~m}$ was not associated with hospitalization due to exacerbation in subjects with COPD.

The efficacy of inhaled bronchodilators and corticosteroids in the treatment of severe COPD and prevention of exacerbations was extensively studied. ${ }^{37-40}$ However, our data suggest that patients with severe COPD will continue to sustain frequent exacerbations notwithstanding aggressive maintenance inhaled therapy. In addition, the absence of significant differences in terms of the Charlson comorbidity index and non-pulmonary medication use, between the 2 groups, reduces the presence of potentially confounding comorbid conditions.

Here some limitations need to be taken into account. The modest sample size is a major limitation of our study. The retrospective and cross-sectional model of the cohort, as well as the use of patient-reported exacerbations, predisposes our study to recall bias and misclassification between case and control status. The choice to select only subjects with severe air-flow obstruction on one hand selects a uniform cohort, but it also limits the generalization of our conclusions. On the contrary, the review of medical records to verify reported exacerbations and the presence of strict exclusion criteria were an advantage of our study 


\section{Factors Associated With Frequent COPD Exacerbator Phenotype}

design. In particular, the exclusion of patients with a history of asthma reduces the percentage of subjects with asthma-COPD overlap syndrome in our population, a relevant clinical population affected by more frequent and severe respiratory exacerbations. ${ }^{41}$

\section{Conclusions}

Despite some limitations, our study suggests that static hyperinflation and respiratory disability, measured by Motley index and mMRC, respectively, as the multidimensional BODE index staging system, were independently associated with frequent exacerbation status in our subjects with severe COPD. Future prospective studies should investigate the effect of static hyperinflation on the risk of frequent exacerbations.

\section{REFERENCES}

1. Mathers CD, Loncar D. Projections of global mortality and burden of disease from 2002 to 2030. PLoS Med 2006;3(11):e442.

2. Vanfleteren LE, Spruit MA, Groenen M, Gaffron S, van Empel VP, Bruijnzeel PL, et al. Clusters of comorbidities based on validated objective measurements and systemic inflammation in patients with chronic obstructive pulmonary disease. Am J Respir Crit Care Med 2013;187(7):728-735.

3. Bauerle O, Chrusch CA, Younes M. Mechanisms by which COPD affects exercise tolerance. Am J Respir Crit Care Med 1998;157(1): 57-68.

4. Donaldson GC, Seemungal TA, Bhowmik A, Wedzicha JA. Relationship between exacerbation frequency and lung function decline in chronic obstructive pulmonary disease. Thorax 2002;57(10):847852.

5. Seemungal TA, Donaldson GC, Paul EA, Bestall JC, Jeffries DJ, Wedzicha JA. Effect of exacerbation on quality of life in patients with chronic obstructive pulmonary disease. Am J Respir Crit Care Med 1998;157(5 Pt 1):1418-1422.

6. Soler-Cataluña JJ, Martínez-García MA, Román Sánchez P, Salcedo E, Navarro M, Ochando R. Severe acute exacerbations and mortality in patients with chronic obstructive pulmonary disease. Thorax 2005; 60(11):925-931.

7. Cote CG, Dordelly LJ, Celli BR. Impact of COPD exacerbations on patient-centered outcomes. Chest 2007;131(3):696-704.

8. Foreman MG, DeMeo DL, Hersh CP, Reilly JJ, Silverman EK. Clinical determinants of exacerbations in severe, early-onset COPD. Eur Respir J 2007;30(6):1124-1130.

9. Burgel PR, Nesme-Meyer P, Chanez P, Caillaud D, Carrè P, Perez T, et al. Cough and sputum production are associated with frequent exacerbations and hospitalizations in COPD subjects. Chest 2009; 135(4):975-982.

10. Donaldson GC, Wedzicha JA. COPD exacerbations: 1: epidemiology. Thorax 2006;61(2):164-168.

11. Niewoehner DE, Lokhnygina Y, Rice K, Kuschner WG, Sharafkhaneh A, Sarosi GA, et al. Risk indexes for exacerbations and hospitalizations due to COPD. Chest 2007;131(1):20-28.

12. Wan ES, DeMeo DL, Hersh CP, Shapiro SD, Rosiello RA, Sama SR, et al. Clinical predictors of frequent exacerbations in subjects with severe chronic obstructive pulmonary disease (COPD). Respir Med 2011;105(4):588-594
13. Oh YM, Sheen SS, Park JH, Jin UR, Yoo JW, Seo JB, et al. Emphysematous phenotype is an independent predictor for frequent exacerbation of COPD. Int J Tuberc Lung Dis 2014;18(12):1407-1414.

14. Faganello MM, Tanni SE, Sanchez FF, Pelegrino NR, Lucheta PA, Godoy I. BODE index and GOLD staging as predictors of 1-year exacerbation risk in chronic obstructive pulmonary disease. Am J Med Sci 2010;339(1):10-14.

15. Marin JM, Carrizo SJ, Casanova C, Martinez-Camblor P, Soriano JB, Agusti AG. Prediction of risk of COPD exacerbations by the bode index. Respir Med 2009;103(3):373-378.

16. Xu W, Collet JP, Shapiro S, Lin Y, Yang T, Platt RW, et al. Independent effect of depression and anxiety on chronic obstructive pulmonary disease exacerbations and hospitalizations. Am J Respir Crit Care Med 2008;178(9):913-920.

17. Groenewegen KH, Postma DS, Hop WC, Wielders PL, Schlösser NJ, Wouters EF, et al. Increased systemic inflammation is a risk factor for COPD exacerbations. Chest 2008;133(2):350-357.

18. Hurst JR, Vestbo J, Anzueto A, Locantore N, Müllerova H, TalSinger R, et al. Susceptibility to exacerbation in chronic obstructive pulmonary disease. N Engl J Med 2010;363(12):1128-1138.

19. Global Initiative for Chronic Obstructive Lung Disease. Global strategy for the diagnosis, management, and prevention of chronic obstructive pulmonary disease. Updated 2011. http://goldcopd.org/.

20. Vestbo J, Hurd SS, Agustí AG, Jones PW, Vogelmeier C, Anzueto A, et al. Global strategy for the diagnosis, management, and prevention of chronic obstructive pulmonary disease: GOLD executive summary. Am J Respir Crit Care Med 2013;187(4):347-365.

21. Miller MR, Hankinson J, Brusasco V, Burgos F, Casaburi R, Coates A, et al. Standardization of spirometry. Eur Respir J 2005;26(2):319338 .

22. Bestall JC, Paul EA, Garrod R, Garnham R, Jones PW, Wedzicha JA. Usefulness of the Medical Research Council (MRC) dyspnoea scale as a measure of disability in patients with chronic obstructive pulmonary disease. Thorax 1999;54(7):581-586.

23. ATS Committee on Proficiency Standards for Clinical Pulmonary Function Laboratories. ATS statement: guidelines for the six-minute walk test. Am J Respir Crit Care Med 2002;166(1):111-117.

24. Celli BR, Cote CG, Marin JM, Casanova C, Montes de Oca M, Mendez RA, et al. The body-mass index, airflow obstruction, dyspnea, and exercise capacity index in chronic obstructive pulmonary disease. N Engl J Med 2004;350(10):1005-1012.

25. Charlson ME, Pompei P, Ales KL, MacKenzie CR. A new method of classifying prognostic comorbidity in longitudinal studies: development and validation. J Chronic Dis 1987;40(5):373-383.

26. Tantucci C, Donati P, Nicosia F, Bertella E, Redolfi S, De Vecchi M, et al. Inspiratory capacity predicts mortality in patients with chronic obstructive pulmonary disease. Respir Med 2008;102(4):613-619.

27. Calverley PM, Koulouris NG. Flow limitation and dynamic hyperinflation: key concepts in modern respiratory physiology. Eur Respir J 2005;25(1):186-199.

28. Eltayara L, Becklake MR, Volta CA, Milic-Emili J. Relationship between chronic dyspnea and expiratory flow limitation in patients with chronic obstructive pulmonary disease. Am J Respir Crit Care Med 1996;154(6 Pt 1):1726-1734.

29. Eltayara L, Ghezzo H, Milic-Emili J. Orthopnea and tidal expiratory flow limitation in patients with stable COPD. Chest 2001;119(1):99104.

30. O'Donnell DE. Hyperinflation, dyspnea, and exercise intolerance in chronic obstructive pulmonary disease. Proc Am Thorac Soc 2006; 3(2):180-184

31. Jones PW, Adamek L, Nadeau G, Banik N. Comparisons of health status scores with MRC grades in COPD: implications for the GOLD 2011 classification. Eur Respir J 2013;42(3):647-654. 


\section{Factors Associated With Frequent COPD Exacerbator Phenotype}

32. Martinez FJ, Foster G, Curtis JL, Criner G, Weinmann G, Fishman A, et al. Predictors of mortality in patients with emphysema and severe airflow obstruction. Am J Respir Crit Care Med 2006;173(12):1326-1334.

33. Cote C, Casanova C, Marin JM, et al. The BODE index and the St. George's questionnaire: associations and survival in COPD. Proc Am Thoracic Soc 2006;3:A851.

34. Pinto-Plata VM, Cote C, Cabral H, Taylor J, Celli BR. The 6-min walk distance: change over time and value as a predictor of survival in severe COPD. Eur Respir J 2004;23(1):28-33.

35. Spruit MA, Polkey MI, Celli B, Edwards LD, Watkins ML, PintoPlata V, et al. Predicting outcomes from 6-minute walk distance in chronic obstructive pulmonary disease. J Am Med Dir Assoc 2012; 13(3):291-297.

36. Polkey MI, Spruit MA, Edwards LD, Watkins ML, Pinto-Plata V, Vestbo J, et al. Six-minute-walk test in chronic obstructive pulmonary disease: minimal clinically important difference for death or hospitalization. Am J Respir Crit Care Med 2013;187(4):382-386.
37. Appleton S, Poole P, Smith B, Veale A, Lasserson TJ, Chan MM. Long-acting $\beta_{2}$ agonists for poorly reversible chronic obstructive pulmonary disease. Cochrane Database Syst Rev 2006;(3): CD001104.

38. Barr RG, Bourbeau J, Camargo CA, Ram FS. Inhaled tiotropium for stable chronic obstructive pulmonary disease. Cochrane Database Syst Rev 2005;(2):CD002876.

39. Nannini LJ, Lasserson TJ, Poole P. Combined corticosteroid and long-acting $\beta_{2}$-agonist in one inhaler versus long-acting $\beta_{2}$ agonists for chronic obstructive pulmonary disease. Cochrane Database Syst Rev 2012;(9):CD006829.

40. Yang IA, Clarke MS, Sim EH, Black PN, Lasserson TJ. Inhaled corticosteroids for stable chronic obstructive pulmonary disease. Cochrane Database Syst Rev 2012;(7):CD002991.

41. Hardin M, Silverman EK, Barr RG, Hansel NN, Schroeder JD, Make $\mathrm{BJ}$, et al. The clinical features of the overlap between COPD and asthma. Respir Res 2011;12:127. 